SRĐAN CVETKOVIĆ, istraživač-saradnik

Institut za savremenu istoriju

Beograd, Trg Nikole Pašića $11 \quad$ UDK 323.281(497.11)"1944/1945"(093.2)

$341.322 .5(497.113) " 1944 / 1945 "(093.2)$

\title{
PREGLED UHAPŠENIH I STRELJANIH LICA OD OZNE NA TERITORIJI VOJVODINE DO 20. JUNA $1945^{*}$
}

Istraživanje i objavljivanje građe iz arhiva službi bezbednosti, koje je u mnogome odmaklo u bivšim republikama SFRJ, u Srbiji je tek na početku. ${ }^{1}$ Taj zadatak postaje važniji kada se zna stepen centralizovanosti policijsko-bezbednosnog aparata na kraju i neposredno posle Drugog svetskog rata. Iz tih razloga očekujemo da se u beogradskim arhivima (najviše Vojnom arhivu i Arhivu Srbije - građa BIA) nalaze najrelevantniji dokumenti, pre svega oni koji se odnose na političku represiju. Značaj objavljivanja dokumenata iz ovih arhiva je teško preceniti kada je u pitanju ovaj dinamičan ali i još uvek „mračan“ istorijski period, naročito dugogodišnje tabu teme kao što su politička represija, uloga i način funkcionisanja službi bezbednosti. Ova vrsta građe na osnovu odluke Vlade Srbije do nedavno je bila dostupna samo pojedinim državnim komisijama, ${ }^{2}$ dok se najavljuje mogućnost skorog korišćenja i u naučnoistraživačke svrhe.

Nasuprot uvreženom mišljenju u naučnoj i široj javnosti, o hapšenim, streljanim i odbeglim licima u prvim posleratnim godinama ipak se vodila detaljna i precizna dokumentacija. Takođe, protivno nekim pretpostavkama izgleda da je dobar deo takve građe preživeo i veliku čistku arhivskih dokumenata Službe

* Zbog ograničenosti prostora, potpun i detaljan spisak uhapšenih i streljanih na području Vojvodine do 20. juna 1945. biće objavljen ove godine u tematskom broju časopisa Hereticus, posvećenom tajnim grobnicama.

${ }^{1}$ U Hrvatskoj se od 2006. objavljuju dokumenti OZN-e za Hrvatsku. U toku je priprema IV toma, a do sada je izašlo: Dokumenti - partizanska i komunistička represija u Hrvatskoj I, Dalmacija, Zagreb 2006; Dokumenti - partizanska i komunistička represija u Hrvatskoj II, Slavonija i Srem, Zagreb 2007; Dokumenti - Partizanska i komunistička represija u Hrvatskoj III, Zagreb i središnja Hrvatska, Zagreb 2008.

${ }^{2}$ Vlada Republike Srbije, na sednici od 9. jula 2009, donela je odluku o osnivanju Državne komisije za pronalaženje i obeležavanje svih tajnih grobnica u kojima se nalaze posmrtni ostaci streljanih posle oslobođenja 1944 (skraćeno Državna komisija za tajne grobnice ubijenih posle 12. septembra 1944), sa konstitutivnom sednicom održanom 12. novembra 2009. godine. U tom smislu, Vlada Republike Srbije je na sednici od 29. aprila 2010. donela Odluku o skidanju oznaka tajnosti sa dokumenata iz nadležnosti Vlade, koji se odnose na činjenice kada, gde, kako i koliko je lica pobijeno na teritoriji Srbije posle 12. septembra 1944. 
bezbednosti posle 1966. i pada Aleksandra Rankovića. ${ }^{3} \mathrm{U}$ predatoj arhivskoj građi BIA u Arhivu Srbije mogu se naći detaljni spiskovi, dosijei i čitave ukoričene ,knjige streljanih “, ,antinarodnih elemenata“ i ,neprijatelja današnjice“. U ovim dokumentima se kao kvalifikacija pored imena likvidiranih naješće nalazi sasvim šturo obrazloženje: „DM“ (Pokret Draže Mihailovića), SDS, ZBOR, ,narodni neprijatelj “, jatak, ili saradnik. Za žene: špijunka, jatak, prostitutka... Nažalost, nije bio redak slučaj da se među streljanima nalaze i maloletna lica. Bilo je slučajeva da se greškom strelja lice sa istim imenom i prezimenom, a potom se u izveštaju kaže: ,,.. nema veze, $i$ on je bio neprijatelj današnjice “. ${ }^{4}$ Obično su streljane najpre evidentirali lokalni organi OZN-e i narodnooslobodilački odbori, a kasnije su spiskovi dostavljani višim instancama Službe bezbednosti. Tokom 1946, a naročito posle sukoba sa Informacionim biroom 1948. godine, mesni organi OZN-e dobili su zadatak da sve spiskove srede i izveštaje dostave višim instancama, najverovatnije zbog mapiranja ,unutrašnjih neprijatelja" u koje su potencijalno ubrajane i porodice streljanih. ${ }^{5}$

Dokument koji donosimo nastao je 1945. godine i predstavlja tabelaran pregled broja lica koja su uhapsili ili streljali organi OZN-e na teritoriji Vojvodine u periodu od oslobođenja oktobra 1944. do 20. juna 1945, kao i prateći kratak izveštaj o ratnim zločinima i samovolji u kažnjavanju ratnih zarobljenika na teritoriji Srema i Slavonije od strane vojnih jedinica. Ovaj dokument OZN-e za Vojvodinu sadrži pregled 14.069 lica, od kojih je najmanje 10.360 streljano u prvim danima od OZN-e i vojnih jedinica (nedostaju svi koje je streljala vojska). ${ }^{6}$ Ovaj sumaran pregled može doprineti preciznijem sagledavanju broja likvidiranih lica na teritoriji Vojvodine tokom 1944-1945, kao i metoda i tehnologije represije (u kojem stepenu je bila institucionalizovana a u kojem se radilo o anarhičnosti, samovolji i preterivanju pojedinaca na terenu). Treba istaći da navedena brojka predstavlja samo donju granicu stradalih i da njoj treba dodati broj lica koje su streljale vojne jedinice kao i broj kasnije sudski procesuiranih kako bi se do kraja sagledale razmere represije. Broj ukupnih žrtava mora registrovati i na drugi način ubijene u logorima (izgladnjivanje, namerno nelečenje...) kojih je prema svim dosadašnjim istraživanjima svakako više nego streljanih. ${ }^{7}$

\footnotetext{
${ }^{3}$ Više o uništavanju arhivske građe SDB u: Srđan Cvetković, Kako je spaljeno pet kilometara dosijea UDB-e, Arhiv, 1/2-2008, Arhiv Jugoslavije, Beograd 2008, 71-85.

${ }^{4}$ Arhiv Srbije (AS), Arhivska građa BIA, f. 154, Spisak likvidiranih antinarodnih elemenata, str. 9.

${ }^{5}$ Opunomoćenik UDB-e za srez Posavotamnavski Milutin Popović poziva se na Uputstvo st. pov. 1439/1948. kojim se traži od vrha OZN-e da se dostave sređeni i popunjeni kartoni za lica koja su osuđena ili streljana u periodu 1941-1948. Luka Dragojlović, opunomoćenik sreza Račanskog za Bajinu Baštu se poziva na Uputstvo br. 1851 od 9. novembra 1948, dok opunomoćstvo sreza Ljubićkog ima iste zahteve prema MNO Rošci itd. - AS, Arhivska građa BIA, fasc. 140, Zbirka dokumenata o aktivnostima četnika, 16 spiskova četnika DM koji su likvidirani po oslobođenju; IAČ NOO Rošci, K-1, reg. br. 1134/46.

${ }^{6}$ AS, Arhivska građa BIA, 75, Pregled uhapšenih, prošlih kroz zatvor i streljanih od oslobođenja do 20. 06. 1945. godine na teritoriji Vojvodine.

7 Državna komisija za tajne grobnice ubijenih posle 12. septembra 1944. prikupila je u prvoj godini rada podatke za više od 20.000 stradalih i nestalih lica na teritoriji cele Srbije. Komisi-
} 
Kritičkim čitanjem ovog izveštaja mogu se uočiti i izvesne simetrije represije na liniji Srbi - Hrvati, kao i činjenica da je dobar deo likvidacija u Vojvodini bio rukovođen golom osvetom i anarhičnom represijom pojedinaca i grupa, koje državni aparat nije mogao lako da obuzda. Objavljivanje ovog dokumenta ima i poseban društveno-politički značaj u svetlu činjenice da je pitanje broja žrtava u Vojvodini (pre svega Mađara i Nemaca) predmet interesovanja političkih krugova u Mađarskoj i pojedinih nevladinih organizacija. U tom smislu, određeni politički činioci i istraživači često su koristili ovo pitanje kao predmet političke instrumentalizacije, preuveličavanja i elemenat građenja mitova, ili u suprotnom smeru: za minimiziranje i negaciju. Nadamo se da će dokument koji objavljujemo, kao i predstojeća istraživanja Državne komisije za tajne grobnice uz sistematsko objavljivanja do sada nepristupačne dokumentacije razvejati političke magle koje se grade na dugogodišnjim tabuima i doprineti objektivnijem suočavanju društva sa ratnim zločinima i autoritarnim nasleđem, kao i daljem razvijanju dobrosusedskih odnosa na pravim temeljima.

\section{ODELJENJE ZAŠTITE NARODA (OZNA) ZA VOJVODINU FEDERATIVNE JUGOSLAVIJE}

Br. pov. 731

20.06. 1945. Novi Sad

\section{OZNA MINISTARSTVA NARODNE ODBRANE FEDERATIVNE JUGOSLAVIJE}

U prilogu vam šaljemo pregled uhapšenika prošlih kroz zatvor i streljanih od oslobođenja do 20. VI. 1945 g. na teritoriji Vojvodine.

Ukupan broj streljanih Hrvata u Sremu znatno se po visio, u odnosu na ukupan broj streljanih Srba, greškom učinjenom u Vukovaru, gde je OZN-a za Srem na svoju ruku streljala 105 Hrvata/ustaša i agenata/. Zbog ove greške, a naročito zbog neiskrenosti, smenjen je načelnik OZN-e za Srem.

Smrt fašizmu, sloboda narodu!

NAČELNIK Odeljenja zaštite naroda

Za Vojvodinu Major

Petar Reljić

\footnotetext{
ji je ustupljena i baza od preko 27.000 stradalih (većim delom u logorima) posle 12. septembra 1944, koju je popisao Anketni odbor Skupštine Vojvodine. U narednom periodu ta baza treba da bude inkorporirana u jedinstvenu bazu podataka, dostupnu građanima preko veb sajta Komisije. Na putu ka istini, Imenik stradalih osoba na teritoriji Vojvodine 1941-1948, Novi Sad 2008.
} 
095-9-1945

900-9-1945

-1 -

Izveštaj o ubijanju ratnih zarobljenika

1 juna t. g. 14 četa IV bataljona II vojvođanske brigade KNOJ-a primila je 4200 zarobljenika /ustaše/. Istoga dana krenuli su odmah na put prema Vinkovcima. Na traženje OZNE u Vinkovcima predali su 105 zarobljenika na što su dobili potvrdu. Kada su stigli u Šidske Banovce jedan od ustaša je ubijen koji je pokušao begstvo. U selu Lazanu dozvolili su narodu da mlate zarobljenike, tako da je bilo 10 pretučeno i dalje nisu bili sposobni za pokret, te su ih borci pobili.

U Šid su stigli 7 juna t. g. zarobljenici su bili premoreni, nisu mogli dalje vršiti pokret, nego su ostali u Šidu jedan dan i noć. Krenuli su 8-og uveče. Kada su stigli u Šid narod se okupio oko njih i počeo ih je tući, našta četa koja ih je sprovodila nije ništa preduzela, nego je na šta više i nagovarala narod da ih tuče. Tako je sekretar partiske ćelije drug Dušan Stanković pitao stražare da li može i on tući, našta su mu oni odgovorili da može. Stanković je uzeo pušku, ispalio je dva do tri metka u gomilu zarobljenika, koji su išli da piju vode. Stanković je iz Sremske Rače, ali je tog dana bio poslom u Šidu, na savjetovanju kod Sremskog Komiteta. Osim naroda u Šidu, zarobljenike su počeli tući i sreski odbor USAOJ-a i još neki naši rukovodeći drugovi.

Zatim je kolona krenula kroz Gibarac i Kukojevce. U tim selima zarobljenim neprijateljskim vojnicima nije se ništa desilo. Kad su stigli u Kuzmin, a to je bila peta kolona zarobljenika koja je prolazila kroz selo, prve četiri kolone koje su prošle nije im se ništa desilo, a kad je naišla peta kolona narod je počeo odmah da ih tuče. Sam narod u selu prepoznao je trojicu ustaša iz Čalme, koji su u jesen 1944 g. pobili celu familiju Vladisavljević; komesar čete koja ih je sprovodila odvojio ih je, dozvolio narodu da ih tuče koliko god su hteli. Ta trojica ustaša koji su već bili nesposobni za svaki daljni pokret vojnici su dobili naređenje od komesara da ih pobiju. Zatim su trojica pokušali begstvo, ali su pri tom uhvaćeni i odmah streljani, od te trojice jednog je ubio borac Armaković Vita iz pištolja, a drugog je zaklao, za trećeg nije nam poznato ko ga je ubio. U Kuzminu takođe su tukli omladinci, što su dobili odobrenje od vojnika, koji su im govorili „udrite, šta čekate“. Od Kuzmina do Martinaca poubijano ih je 16 i to na prostoru između ova dva sela.

U samim Martincima narod je takođe na odobrenje vojnika sprovodnika tukao zarobljenike. U samom selu nije ubijen ni jedan. U tom selu zarobljenike najviše su tukle žene. Tek po izlasku iz sela ubijeno je njih petorica, koji nisu mogli dalje da idu. Kad su stigli u Laćerak tamo su takođe zarobljenici bili tučeni, gde su najviše dobili batine od civila. Od Laćarka do Mitrovice takođe je ubijeno 5. U Mitrovicu su došli 9 juna, gde nisu bili tučeni, nego su odmah dobili hranu i vodu, kao i odmor. 9-og noću krenuli su za Rumu. Čim su ušli u grad na- 
rod ih je počeo tući, tako da je jedan od strane vojnika ubijen u centru grada pred hotelom „Krune“. Od Vognja do Rume poubijeno je 16 ustaša. U samoj Rumi među građanstvom koje je tuklo zarobljenike nalazio se i potpredsednik sreskog NOO-a drug Zdravko Vidaković. U samoj Rumi kod tučenja zarobljenika naročito su se isticali ljudi koji nisu ništa dali za NOP, a mogu se smatrati i kao reakcionari. U Rumi postoji jedan deo hrvaskog življa na koga je ovaj postupak prema zarobljenim ustašama vrlo loše delovao, tako da je 10 juna t. g. trebala da se održi konferencija među Hrvatima za stvaranje JNOF-a međutim ta konferencija uopšte nije uspela i na nju je došlo svega 10 osoba, tako tog dana nije ni održana. U Rumi su se ranije Hrvati vrlo dobro odazvali svim konferencijama koje su održavane u gradu.

Od kako je ta četa primila zarobljenike pa do Rume nestalo ih je 77. Kod ubijanja naročito se isticao jedan stražar pod nazivom „Elevator“ koji je iz kolone izvodio jednog po jednog i ubijao. Komesar čete koja ih je sprovodila Dokić Vladimir ubio je trojicu, dok za ostale davao je naređenja da se ubiju.

Četa koja ih je sprovodila na putu sa zarobljenicima vrlo loše su postupali, nisu im dali vode da piju, sve dok nisu stizali na određena mesta gde treba da se odmore, odobravali su i nagovarali su sam narod da ih tuče. Jedini komandir čete pod imenom Čičak u nekoliko momenata pokušao je da otera narod, ali ni on sam nije mogao ništa s obzirom da je kolona bila vrlo dugačka. Iz Rume su krenuli 10 juna za Banat. Dalje se nije dešavalo da ih je iko tukao, a niti ubijao. Stanković Duško sekretar mesne ćelije u Sremskoj Rači koji je na zarobljenike pucao u Šidu zadržan je u OZNI za Srem u Mitrovici.

13. juna 1945

Šef III Otseka OZN-e za Vojvodinu

Major

Dušan Olujić

(potpis) 


\section{PREGLED}

\section{UHAPŠENIKA PROŠLIH KROZ ZATVOR I STRELJANIH OD OSLOBOĐENJA DO 20. JUNA 1945. NA TERITORIJI VOJVODINE}

\begin{tabular}{|l|r|r|r|}
\hline $\begin{array}{c}\text { Odeljenje Otsek za Banat do formiranja odeljenja } \\
\text { OZN-e za Okrug Pančevo i Petrograd }\end{array}$ & \multicolumn{2}{|c|}{$\begin{array}{c}\text { Odeljenje Otsek za Banat } \\
\text { Okružno odeljenje Petrograd }\end{array}$} \\
\hline Četnici & 173 & 6 & \\
\hline Nedićevci & 7 & 0 & \\
\hline Ljotićevci & 7 & 1 & \\
\hline Ustaše & 0 & 0 & \\
\hline Aktivisti okupatora & 248 & 29 & \\
\hline Ratni zločinci & 239 & 18 & \\
\hline Gestapovci & 0 & 0 & \\
\hline Agenti & 192 & 2 & \\
\hline Špijuni & 1 & 24 & \\
\hline Nemački vojnici & 5 & 0 & \\
\hline Saboteri & 0 & 5 & \\
\hline Dezerteri & 3 & 37 & \\
\hline Šverceri & 0 & 0 & \\
\hline Kulturbund & 190 & 51 & \\
\hline Belogardejci & 45 & 0 & \\
\hline Pljačkaši & 7 & 0 & \\
\hline Članovi Gvozdene garde & 3 & 0 & \\
\hline Uhapšeni zbog ubistva & 0 & 0 & \\
\hline Razne političke i druge krivice & 0 & 0 & \\
\hline Ukupno po rešenju & $\mathbf{5 6 1}$ & $\mathbf{1 4 9}$ & \\
\hline Ukupno po nacionalnosti & $\mathbf{1 6 6 7}$ & $\mathbf{3 2 2}$ & \\
\hline Sve ukupno & $\mathbf{1 6 6 7}$ & $\mathbf{3 2 2}$ & \\
\hline Primedba & $\mathbf{1 6 6 7}$ & $\mathbf{3 2 2}$ & \\
\hline
\end{tabular}

\begin{tabular}{|l|r|}
\hline \multicolumn{2}{|c|}{ Okružno odeljenje Pančevo } \\
\hline Četnici & 20 \\
\hline Nedićevci & 4 \\
\hline Ljotićevci & 0 \\
\hline Ustaše & 1 \\
\hline Aktivisti okupatora & 41 \\
\hline Ratni zločinci & 4 \\
\hline Gestapovci & 1 \\
\hline Agenti & 2 \\
\hline Špijuni & 1 \\
\hline Nemački vojnici & 10 \\
\hline Saboteri & 0 \\
\hline Dezerteri & 16 \\
\hline Šverceri & 0 \\
\hline
\end{tabular}




\begin{tabular}{|l|r|}
\hline Kulturbund & 1 \\
\hline Belogardejci & 0 \\
\hline Pljačkaši & 0 \\
\hline Članovi Gvozdene garde & 3 \\
\hline Uhapšeni zbog ubistva & 0 \\
\hline Razne političke i druge krivice & 0 \\
\hline Ukupno po rešenju & $\mathbf{5 4}$ \\
\hline Ukupno po nacionalnosti & $\mathbf{1 5 8}$ \\
\hline Sve ukupno & $\mathbf{1 5 8}$ \\
\hline Primedba & $\mathbf{1 5 8}$ \\
\hline
\end{tabular}

\begin{tabular}{|l|r|}
\hline \multicolumn{2}{|c|}{ Otsek za Bačku i Baranju (do formiranja okružnih odeljenja) } \\
Novi Sad, Sombor i Subotica
\end{tabular}

\begin{tabular}{|l|r|}
\hline \multicolumn{2}{|c|}{ Okružno odeljenje Novi Sad } \\
\hline Četnici & 5 \\
\hline Nedićevci & 1 \\
\hline Ljotićevci & 1 \\
\hline Ustaše & 0 \\
\hline Aktivisti okupatora & 32 \\
\hline
\end{tabular}




\begin{tabular}{|l|r|}
\hline Ratni zločinci & 10 \\
\hline Gestapovci & 0 \\
\hline Agenti & 0 \\
\hline Špijuni & 0 \\
\hline Nemački vojnici & 0 \\
\hline Saboteri & 1 \\
\hline Dezerteri & 4 \\
\hline Šverceri & 0 \\
\hline Kulturbund & 4 \\
\hline Belogardejci & 0 \\
\hline Pljačkaši & 2 \\
\hline Članovi Gvozdene garde & 1 \\
\hline Uhapšeni zbog ubistva & 0 \\
\hline Razne političke i druge krivice & 0 \\
\hline Ukupno po rešenju & $\mathbf{3 8}$ \\
\hline Ukupno po nacionalnosti & $\mathbf{1 0 8}$ \\
\hline Sve ukupno & $\mathbf{1 0 8}$ \\
\hline Primedba & $\mathbf{1 0 8}$ \\
\hline
\end{tabular}

\begin{tabular}{|l|r|}
\hline \multicolumn{2}{|c|}{ Okružno odeljenje Sombor } \\
\hline Četnici & 0 \\
\hline Nedićevci & 0 \\
\hline Ljotićevci & 0 \\
\hline Ustaše & 2 \\
\hline Aktivisti okupatora & 7 \\
\hline Ratni zločinci & 10 \\
\hline Gestapovci & 2 \\
\hline Agenti & 0 \\
\hline Špijuni & 0 \\
\hline Nemački vojnici & 69 \\
\hline Saboteri & 20 \\
\hline Dezerteri & 1 \\
\hline Šverceri & 1 \\
\hline Kulturbund & 1 \\
\hline Belogardejci & 0 \\
\hline Pljačkaši & 3 \\
\hline Članovi Gvozdene garde & 0 \\
\hline Uhapšeni zbog ubistva & 0 \\
\hline Razne političke i druge krivice & 0 \\
\hline Ukupno po rešenju & $\mathbf{8 5}$ \\
\hline Ukupno po nacionalnosti & $\mathbf{2 0 1}$ \\
\hline Sve ukupno & $\mathbf{2 0 1}$ \\
\hline Primedba & $\mathbf{2 0 1}$ \\
\hline
\end{tabular}




\begin{tabular}{|l|r|}
\hline \multicolumn{2}{|c|}{ Okružno odeljenje Subotica } \\
\hline Četnici & 8 \\
\hline Nedićevci & 2 \\
\hline Ljotićevci & 0 \\
\hline Ustaše & 1 \\
\hline Aktivisti okupatora & 23 \\
\hline Ratni zločinci & 11 \\
\hline Gestapovci & 1 \\
\hline Agenti & 3 \\
\hline Špijuni & 0 \\
\hline Nemački vojnici & 8 \\
\hline Saboteri & 2 \\
\hline Dezerteri & 0 \\
\hline Šverceri & 0 \\
\hline Kulturbund & 3 \\
\hline Belogardejci & 0 \\
\hline Pljačkaši & 12 \\
\hline Članovi Gvozdene garde & 0 \\
\hline Uhapšeni zbog ubistva & 0 \\
\hline Razne političke i druge krivice & 0 \\
\hline Ukupno po rešenju & $\mathbf{4 4}$ \\
\hline Ukupno po nacionalnosti & $\mathbf{1 1 8}$ \\
\hline Sve ukupno & $\mathbf{1 1 8}$ \\
\hline Primedba & $\mathbf{1 1 8}$ \\
\hline
\end{tabular}

\begin{tabular}{|l|r|}
\hline \multicolumn{2}{|c|}{ Odeljenje za grad Novi Sad } \\
\hline Četnici & 49 \\
\hline Nedićevci & 4 \\
\hline Ljotićevci & 5 \\
\hline Ustaše & 12 \\
\hline Aktivisti okupatora & 114 \\
\hline Ratni zločinci & 334 \\
\hline Gestapovci & 1 \\
\hline Agenti & 46 \\
\hline Špijuni & 2 \\
\hline Nemački vojnici & 10 \\
\hline Saboteri & 3 \\
\hline Dezerteri & 8 \\
\hline Šverceri & 2 \\
\hline Kulturbund & 57 \\
\hline Belogardejci & 40 \\
\hline Pljačkaši & 7 \\
\hline Članovi Gvozdene garde & 1 \\
\hline Uhapšeni zbog ubistva & 0 \\
\hline
\end{tabular}




\begin{tabular}{|l|r|}
\hline Razne političke i druge krivice & 0 \\
\hline Ukupno po rešenju & 199 \\
\hline Ukupno po nacionalnosti & $\mathbf{8 9 8}$ \\
\hline Sve ukupno & $\mathbf{8 9 8}$ \\
\hline Primedba & $\mathbf{8 9 8}$ \\
\hline
\end{tabular}

\begin{tabular}{|l|r|}
\hline \multicolumn{2}{|c|}{ Odeljenje OZN-e Srem do formiranja OZN-e za grad Zemun } \\
\hline Četnici & 27 \\
\hline Nedićevci & 1 \\
\hline Ljotićevci & 0 \\
\hline Ustaše & 487 \\
\hline Aktivisti okupatora & 71 \\
\hline Ratni zločinci & 0 \\
\hline Gestapovci & 5 \\
\hline Agenti & 3 \\
\hline Spijuni & 0 \\
\hline Nemački vojnici & 35 \\
\hline Saboteri & 0 \\
\hline Dezerteri & 1 \\
\hline Šrerceri & 0 \\
\hline Kulturbund & 538 \\
\hline Belogardejci & 0 \\
\hline Pljačkaši & 9 \\
\hline Članovi Gvozdene garde & 0 \\
\hline Uhapšeni zbog ubistva & 0 \\
\hline Razne političke i druge krivice & 0 \\
\hline Ukupno po rešenju & $\mathbf{5 1 1}$ \\
\hline Ukupno po nacionalnosti & $\mathbf{1 6 8 8}$ \\
\hline Sve ukupno & $\mathbf{1 6 8 8}$ \\
\hline Primedba & $\mathbf{1 6 8 8}$ \\
\hline
\end{tabular}

\begin{tabular}{|l|r|}
\hline \multicolumn{2}{|c|}{ Odeljenje za grad Zemun } \\
\hline Četnici & 2 \\
\hline Nedićevci & 1 \\
\hline Ljotićevci & 0 \\
\hline Ustaše & 15 \\
\hline Aktivisti okupatora & 10 \\
\hline Ratni zločinci & 9 \\
\hline Gestapovci & 6 \\
\hline Agenti & 4 \\
\hline Spijuni & 0 \\
\hline Nemački vojnici & 0 \\
\hline Saboteri & 2 \\
\hline
\end{tabular}




\begin{tabular}{|l|r|}
\hline Dezerteri & 1 \\
\hline Šverceri & 0 \\
\hline Kulturbund & 6 \\
\hline Belogardejci & 0 \\
\hline Pljačkaši & 0 \\
\hline Članovi Gvozdene garde & 0 \\
\hline Uhapšeni zbog ubistva & 0 \\
\hline Razne političke i druge krivice & 0 \\
\hline Ukupno po rešenju & $\mathbf{3}$ \\
\hline Ukupno po nacionalnosti & $\mathbf{7 5}$ \\
\hline Sve ukupno & $\mathbf{7 5}$ \\
\hline Primedba & $\mathbf{7 5}$ \\
\hline
\end{tabular}

\section{UKUPNO PROŠLO KROZ ZATVOR NA TERITORIJI VOJVODINE}

\begin{tabular}{|l|r|}
\hline \multicolumn{2}{|c|}{ Odeljenje OZN-e za Vojvodinu } \\
\hline Četnici & 348 \\
\hline Nedićevci & 23 \\
\hline Ljotićevci & 15 \\
\hline Ustaše & 748 \\
\hline Aktivisti okupatora & 958 \\
\hline Ratni zločinci & 2210 \\
\hline Gestapovci & 268 \\
\hline Agenti & 316 \\
\hline Špijuni & 4 \\
\hline Nemački vojnici & 27 \\
\hline Saboteri & 46 \\
\hline Dezerteri & 89 \\
\hline Šverceri & 2 \\
\hline Kulturbund & 1564 \\
\hline Belogardejci & 103 \\
\hline Pljačkaši & 57 \\
\hline Članovi Gvozdene garde & 8 \\
\hline Uhapšeni zbog ubistva & 2 \\
\hline Razne političke i druge krivice & 0 \\
\hline Ukupno po rešenju & $\mathbf{2 0 1 5}$ \\
\hline Ukupno po nacionalnosti & $\mathbf{9 0 6 9}$ \\
\hline Sve ukupno & $\mathbf{9 0 6 9}$ \\
\hline Primedba & $\mathbf{9 0 6 9}$ \\
\hline
\end{tabular}

\begin{tabular}{|l|r|}
\hline \multicolumn{2}{|c|}{ Nemci streljani od naše vojske } \\
\hline koji nisu prošli kroz zatvor & 5000 \\
\hline ukupno po nacionalnosti koji su prošli kroz zatvor & 5360 \\
\hline Ukupno na teritoriji Vojvodine & 10360 \\
\hline
\end{tabular}




\begin{tabular}{|c|c|c|c|c|c|c|c|c|c|c|c|c|c|c|c|c|c|c|c|}
\hline 莺 & $\overrightarrow{0}$ & 苞 & $\begin{array}{l}\overline{0} \\
\overline{0} \\
\overrightarrow{0} \\
\bar{\sigma}\end{array}$ & $\begin{array}{l}\overline{0} \\
\bar{z} \\
\overline{0} \\
\bar{\sigma}\end{array}$ & $\vec{s}$ & $\overrightarrow{\tilde{n}}$ & $\begin{array}{l}\overline{0} \\
\stackrel{\tilde{E}}{\overline{0}} \\
0\end{array}$ & 竞 & $\begin{array}{l}\overline{\vec{\Xi}} \\
\overline{0} \\
\bar{Z}\end{array}$ & $\underset{\Sigma}{\stackrel{E}{E}}$ & 忐 & : & 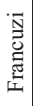 & 刭 & : & 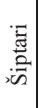 & 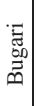 & 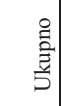 & 苛 \\
\hline $\begin{array}{l}\text { pušteno na } \\
\text { slobodu }\end{array}$ & 648 & 448 & 36 & 38 & 7 & 42 & 1 & 7 & 222 & 354 & 71 & 1 & & 3 & 7 & & 3 & 1888 & \\
\hline prisilan rad & 75 & 72 & 1 & 10 & 1 & 6 & & 4 & 2 & 54 & 9 & & & 1 & 1 & & 1 & 237 & \\
\hline predato sudu & 225 & 170 & 12 & 24 & 3 & 11 & & 5 & 54 & 229 & 11 & & & 10 & 4 & 1 & 1 & 760 & \\
\hline $\begin{array}{l}\text { Upućeno u } \\
\text { NOV }\end{array}$ & 22 & 7 & 2 & 4 & & & & 3 & & 23 & 8 & & & & & 3 & & 72 & \\
\hline $\begin{array}{l}\text { predato } \\
\text { drugim odel- } \\
\text { jenjima } \\
\text { OZNe } \\
\end{array}$ & 73 & 43 & 4 & 1 & 1 & 10 & & 1 & 10 & 24 & 1 & & & & & 1 & & 169 & \\
\hline pod istragom & 24 & 22 & & & & & & & 6 & 7 & & & & 1 & 1 & & & 61 & \\
\hline $\begin{array}{l}\text { upućeni u } \\
\text { logor }\end{array}$ & & 51 & 3 & 4 & 3 & 2 & 1 & & 334 & 39 & 3 & 1 & & 2 & & & & 443 & \\
\hline $\begin{array}{l}\text { izvršili } \\
\text { samoubistvo } \\
\text { u zatvoru } \\
\end{array}$ & & 1 & & & & & & & 1 & & & & & & & & & 2 & \\
\hline robija & & & & 2 & & & & & & 7 & & & & & & & & 9 & \\
\hline $\begin{array}{l}\text { predato Rus- } \\
\text { koj komandi }\end{array}$ & & & & & & 30 & & & & & & & & & & & & 30 & \\
\hline $\begin{array}{l}\text { internirano u } \\
\text { Mađarsku }\end{array}$ & & & & & & & & & & 6 & & & & & & & & 6 & \\
\hline \begin{tabular}{|l|} 
umrlo u \\
zatvoru \\
\end{tabular} & & & & & & & & 1 & & 1 & & & & & & & & 2 & \\
\hline $\begin{array}{l}\text { uhapšeno na } \\
\text { traženje } \\
\text { drugih odel- } \\
\text { jenja OZNe }\end{array}$ & & & & & & & & & & & & & & & 1 & & & 1 & \\
\hline $\begin{array}{l}\text { streljano od } \\
\text { strane N.K. } \\
\text { V.D }\end{array}$ & & & & & & 29 & & & & & & & & & & & & 29 & \\
\hline streljano & 438 & 558 & 2 & 31 & 6 & 68 & & 5 & 1983 & 2240 & 16 & 1 & 1 & 7 & 1 & & 3 & 5360 & \\
\hline Ukupno & 1505 & 1372 & 60 & 114 & 21 & 198 & 2 & 26 & 2612 & 2984 & 119 & 3 & 1 & 24 & 15 & 5 & 8 & 9069 & \\
\hline $\begin{array}{l}\text { streljano od } \\
\text { strane naše } \\
\text { vojske }\end{array}$ & & & & & & & & & 5000 & & & & & & & & & 5000 & \\
\hline sve ukupno & 1505 & 1372 & 60 & 114 & 21 & 198 & 2 & 28 & 7612 & 2984 & 119 & 3 & 1 & 24 & 15 & 5 & 8 & 14069 & \\
\hline
\end{tabular}

Ukupan broj streljanih Hrvata povećao se zbog greške učinjene u Vukovaru (radi se o samovoljnoj likvidaciji 105 ratnih zarobljenika - nap. priređivača) 